\title{
1 Evidence for adaptive morphological plasticity in the Caribbean coral,
}

2 Acropora cervicornis.

3 Wyatt C. Million ${ }^{1}$, Maria Ruggeri ${ }^{1}$, Sibelle O’Donnell ${ }^{1}$, Erich Bartels ${ }^{2}$, Cory J. Krediet ${ }^{3}$, Carly D.

$4 \quad$ Kenkel $^{1}$

$5 \quad{ }^{1}$ Department of Biological Sciences, University of Southern California, Los Angeles, Los

6 Angeles, CA, United States

$7 \quad{ }^{2}$ Elizabeth Moore International Center for Coral Reef Research \& Restoration, Mote Marine

8 Laboratory, Summerland Key, FL, United States

$9{ }^{3}$ Department of Marine Science, Eckerd College, St. Petersburg, FL, United States

10

$11 *$ Corresponding Author:

12 Wyatt C. Million

13 Email: wmillion@usc.edu

14 Address: 3616 Trousdale Parkway, AHF 231 Los Angeles, CA 90089

15

16

17

Keywords: GxE, fragmentation, growth, survival, 3D photogrammetry 


\section{Abstract}

19 Genotype-by-environment interactions $(\mathrm{GxE})$ indicate that variation in organismal traits cannot

20 be explained by fixed effects of genetics or site-specific plastic responses alone. For tropical coral

21 reefs experiencing dramatic environmental change, identifying the contributions of genotype,

22 environment, and GxE on coral performance will be vital for both predicting persistence and

23 developing restoration strategies. We quantified the impacts of G, E, and GxE on the morphology

24 and survival of the endangered coral, A. cervicornis, through an in situ transplant experiment

25 exposing common garden (nursery) raised clones of ten genotypes to nine reef sites in the Florida

26 Keys. By fate-tracking outplants over one year with colony-level 3D photogrammetry, we uncovered significant GxE on coral size and survivorship indicating that no universal winner exists in terms of colony performance. Moreover, the presence of GxE also implies the existence of intraspecific variation in phenotypic plasticity. Rather than differences in mean trait values, we find that individual-level morphological plasticity is adaptive in that the most plastic individuals also exhibited the fastest growth and highest survival. This indicates that adaptive morphological plasticity may continue to evolve, influencing the success of $A$. cervicornis and resulting reef communities in a changing climate. As focal reefs are active restoration sites, the knowledge that variation in phenotype is an important predictor of performance can be directly applied to restoration planning. Taken together, these results establish A. cervicornis as a system for studying the eco-evolutionary dynamics of phenotypic plasticity that also can inform genetic- and environment-based strategies for coral restoration. 


\section{Introduction}

Intraspecific variation in phenotype provides raw material for selection to act on resulting in the evolution of trait means (1). However, trait values may also change as individuals are exposed to different environments via phenotypic plasticity (2). While plastic trait changes typically occur within a generation, they have the ability to alter fitness-related traits and promote acclimation, and are therefore relevant for populations experiencing new or stressful environmental conditions (3-6). Moreover, variation in the degree of plasticity can magnify differences among individuals. In the light of intraspecific variation in plasticity, the evolution of trait means becomes dependent not only on individual trait values but also the environments those individuals face. Long-standing theory supports a role for plasticity in trait evolution (7-9) and the presence of significant intraspecific variation in plasticity, i.e. genotype-by-environment interactions $(\mathrm{GxE})$, suggest that plasticity itself can also evolve (10-12).

The evolution of phenotypic plasticity, and consequently its ecological impacts, can occur if variation in plasticity among individuals results in variation in fitness. Selection is expected to increase plasticity when the benefits of producing an environment-specific phenotype outweigh the fitness consequences arising from either the cost of altering that phenotype, or from the production of an underdeveloped phenotype relative to locally adapted individuals $(13,14)$. Evolutionary models suggest plasticity will be favored in species with high dispersal that will experience predictably high spatial or temporal environmental variation and when the costs of plasticity are low (14). However, limited empirical tests for an adaptive role of plasticity $(12,14)$ provide inconsistent support for model predictions with variation evident among traits, species, and environments (14-16). More experiments that quantify the fitness costs or benefits of plasticity, especially in nonmodel systems, will improve our broad understanding of it's ecological and evolutionary role $(2,10)$ while also uncovering system-specific functions contributing to acclimation to environmental change. This will be particularly important for species of conservation concern, where persistence may be reliant on both adaptive plasticity and the ability of human interventions to leverage it.

Reef-building corals form the base of the most biodiverse marine ecosystems, tropical coral reefs $(17,18)$. The ecological and economic services they provide are determined in part by the complex three-dimensional structures created by the corals themselves (19-21). This structure provides habitat space (22), reduces wave energy (21), and sustains biological diversity and productivity $(19,23)$ which support a multi-billion-dollar tourism industry (24). However, these ecosystem services are being lost as wild populations decline due to natural and anthropogenic factors $(25,26)$. For example, populations of Acropora cervicornis, one of two branching coral species once dominating Caribbean reefs, have declined precipitously since the 1970s (27) contributing to a loss of structural complexity $(28,29)$. This decline has prompted a global effort to understand factors that promote coral survival and persistence under changing ocean conditions. Both differences in fitness-related traits among common-gardened genotypes and of clones under different conditions (30-33) suggests that some individuals or environments could be used to reestablish the structure and function of reefs (34-36). However, as corals experience new conditions, via translocation during reef restoration $(37,38)$ or through climate change $(39$, $40)$, it is unclear whether top performing genotypes will maintain their status $(41,42)$ or if variation in plasticity will result in new 'winners' and 'losers' (43). Therefore, clarifying the role of both the environment and genetic background on coral performance as well as GxE will be critical for leveraging naturally occurring biological variation for the restoration of degraded reefs.

Phenotypic plasticity has been commonly documented in coral morphology $(44,45)$, physiology $(46,47)$, and gene expression $(48,49)$ in response to a variety of abiotic factors, indicating the environmental responsiveness of phenotypes, some of which is correlated with 
fitness-related traits at the population level (50-52). Within-populations, genotype-byenvironment interactions have been reported less frequently $(41,43,53)$ but the relationship between phenotypic plasticity and overall fitness remains unresolved. This gap in knowledge limits both our understanding of the evolutionary potential of plasticity and its role in the natural and human-assisted recovery of coral reefs in a changing climate.

While variation in plasticity exists in wild coral populations $(41,53,54)$, it is unclear if such variation is maintained in restoration corals, like A. cervicornis, that have been propagated in common-garden nurseries for decades. Given that restoration involves outplanting clonal replicates (ramets) across environmentally- diverse, natural reefs $(37,55)$, understanding how individual phenotypes vary can help direct restoration efforts. Previous efforts found no evidence of GxE in A. cervicornis morphology despite strong site and genotype effects on linear growth and survival $(33,37,55)$ but significant variation in bleaching responses among genotypes was observed across natural reefs (43). GxE in fitness-related traits, like bleaching tolerance, suggest that a multisite phenotype may more accurately describe $A$. cervicornis performance in nature.

We rigorously fate-tracked 270 restored coral colonies on natural reefs in a multi-site transplant experiment to test the effect of genotype, environment and their interaction on growth rate, size, risk of fragmentation, and survival (Fig. 1A-C). We uncovered significant GxE in survival and absolute size, measured with 3D photogrammetry, and identified relationships between morphological plasticity, growth, and survival that support the presence of adaptive plasticity in A. cervicornis. Taken together, our results establish a new system in which to investigate the ecological and evolutionary impacts of adaptive plasticity while also informing reef restoration.
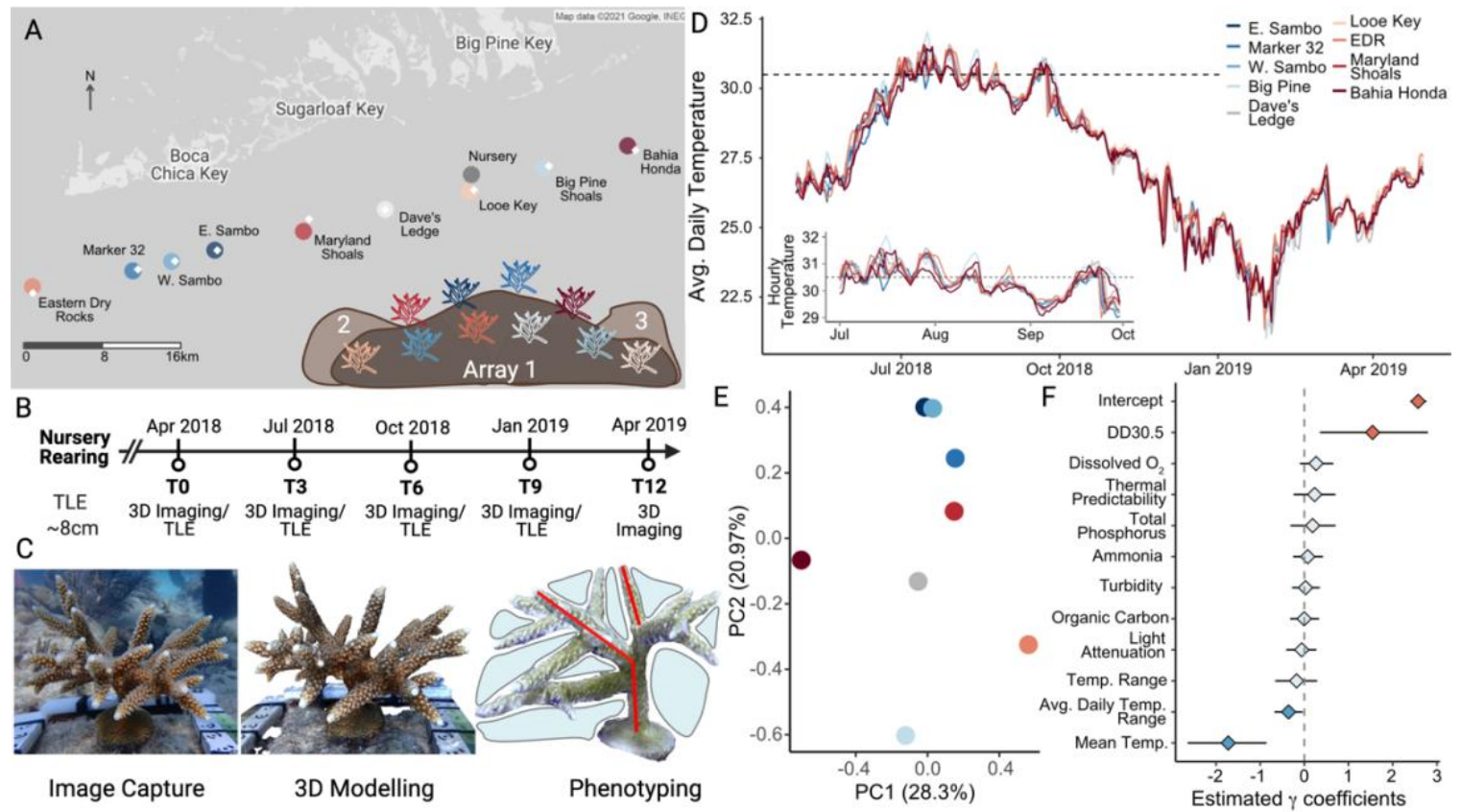

Figure 1: Experimental design and environmental conditions A) Location of outplant sites (Table S1) and the source restoration nursery in the lower Florida Keys, USA. Ten genets (genotypes) of A. cervicornis were outplanted in triplicate to nine reef sites in three sub-arrays. Sites are colored by average survival from dark blue (highest) to dark red (lowest) and the location of site-specific SERC water quality monitoring stations (56) are indicated by the white diamonds. B) Ramets were reared in the nursery to a mean size of $8 \mathrm{~cm}$ and were measured just prior to outplanting in April 2018 C) To obtain growth and morphology data, still images were captured using underwater photography, which were used to build 3D models in Agisoft Metashape, that were subsequently measured for total linear extension (TLE; example 
bioRxiv preprint doi: https://doi.org/10.1101/2022.03.04.483038; this version posted March 6, 2022. The copyright holder for this preprint (which was not certified by peer review) is the author/funder, who has granted bioRxiv a license to display the preprint in perpetuity. It is made available under aCC-BY-NC-ND 4.0 International license.

red lines), surface area $(\mathrm{SA})$, volume $(\mathrm{V})$, and volume of the interstitial space $\left(\mathrm{V}_{\text {inter }}\right.$; example shaded blue area) D) Average daily temperature of each site (colored by survival rank) for the one-year experimental period. Inset shows hourly temperatures from July through September 2018. The dashed line indicates the local bleaching threshold of $30.5^{\circ} \mathrm{C}$. E) Principal components analysis of historical SERC environmental metrics characterizing outplant reef sites (Looe Key is excluded due to missing data) F) Results of a Bayesian negative binomial generalized linear mixed effects model testing the association of eleven uncorrelated environmental parameters on the change in $V_{\text {inter }}$. Horizontal black lines indicate $95 \%$ credible intervals of the posterior distributions. Values above (red) or below (blue) indicate significant association between the variable and the change in $\mathrm{V}_{\text {inter }}$ across sites.

\section{Results}

Ramet survival is a function of genotype, outplant site, and the interaction

Of the 270 outplanted ramets, 48 died and 24 were declared missing leaving 198 surviving ramets at the end of one year. Cox proportional hazard models showed significant effects of genotype $(\mathrm{p}=0.002)$ and site $(\mathrm{p}=0.005)$ on survival. The model including the interaction term, while improving fit, did not converge, so the additive model was used to obtain risk scores for each genotype and site (Table S2-3). On average, Genotype (G) 36 had the highest ramet survival (96\%) while G41 had the lowest (61.5\%) across sites, which incurred a mortality risk 2.6 times that of G36 on average (Fig. 2A, Table S2). Three genotypes (G41, G62, G13) form a group of high risk genets (>2.3x higher mortality risk in comparison to G36) while remaining genets display intermediate risk ranging from nearly equivalent to 1.7 times that of G36 (Fig. 2A, Table S2). Ramets outplanted to Bahia Honda (60\% survival) had a 2.5 times greater risk of mortality than those outplanted to E. Sambo, the site with the highest survival on average (96.4\%, Fig. 2B). Similar to average genotype scores, sites exhibited a continuum of increasing risk with mortality ranging from 1.1 to 2.5 times higher than the reference, E. Sambo, with the highest mortality risk occurring at Bahia Honda (Table S3).

Pairwise correlations of genet survival ranks across sites show the identity of the best surviving genet is not maintained across sites, with most correlations being close to 0 (Fig. 3C). The highest positive correlations (Pearson's correlation $=0.54$ to 0.70 ) were observed among sites with intermediate survival on average (Big Pine, Dave's Ledge, Looe Key, and EDR, Fig. 2B) and not necessarily among geographically neighboring sites (Fig. 1A, S1).
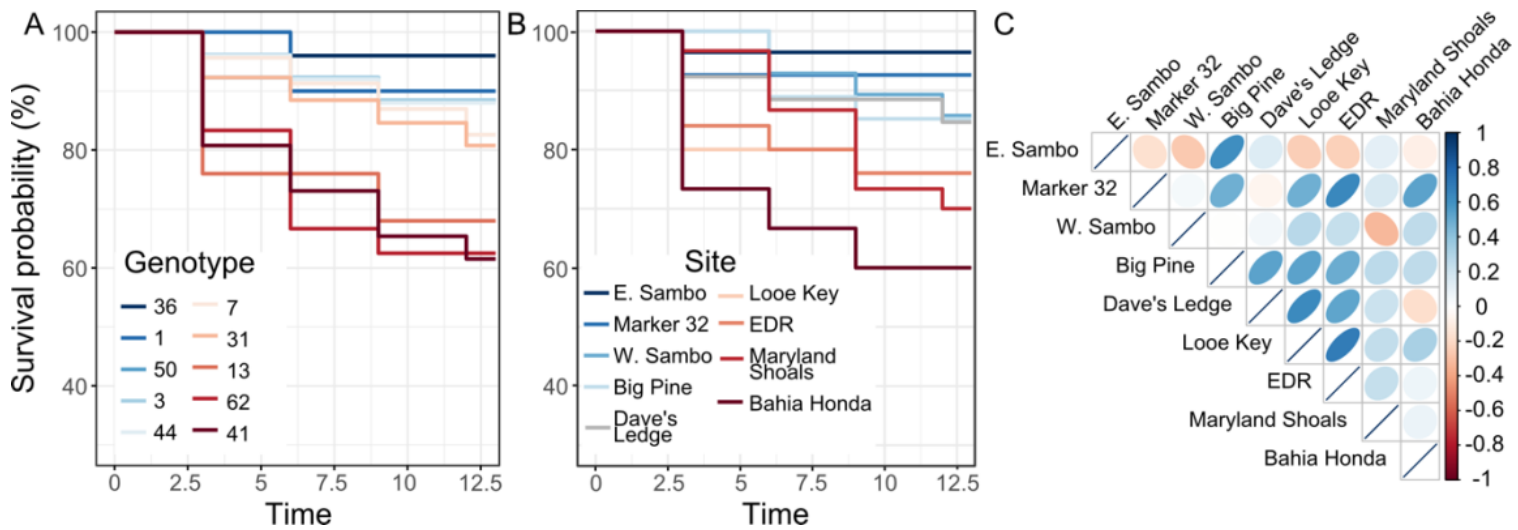

Figure 2: Genotype, environment, and GxE patterns of survival. A) Survival probability for genets and (B) sites over the one-year experimental period. Genets and sites are colored by decreasing overall survival from blue to red. C) Pairwise correlations of genet survival rank across outplant sites. Ellipse shape and color is 
proportional to the strength and direction of the correlation between two sites. Sites are ordered according to survival as in (B).

\section{Non-random fragmentation in A. cervicornis}

We documented 177 instances of fragmentation throughout this experiment. Most events occurred within the first three months post-outplant (84) followed by continually decreasing occurrences in subsequent time periods. Cumulative linked models show a significant effect of genotype and site on the likelihood of fragmentation (Table S4) with Gland Marker 32 experiencing the least amount of breakage among genotypes and sites, respectively (Fig. S2). G44 and Bahia Honda experienced the most breakage among genotypes and sites, respectively, during the outplant period. Of the 177 fragmentation events, only $15.8 \%$ occurred in the same time period that the ramet died, indicating that breakage did not result in immediate mortality. Fragmentation was not overly prevalent in larger size class colonies, and instead was more common in colonies less than $5 \mathrm{~cm}$ and between $5-10 \mathrm{~cm}$ in length according to Fisher Exact tests (Table S5).

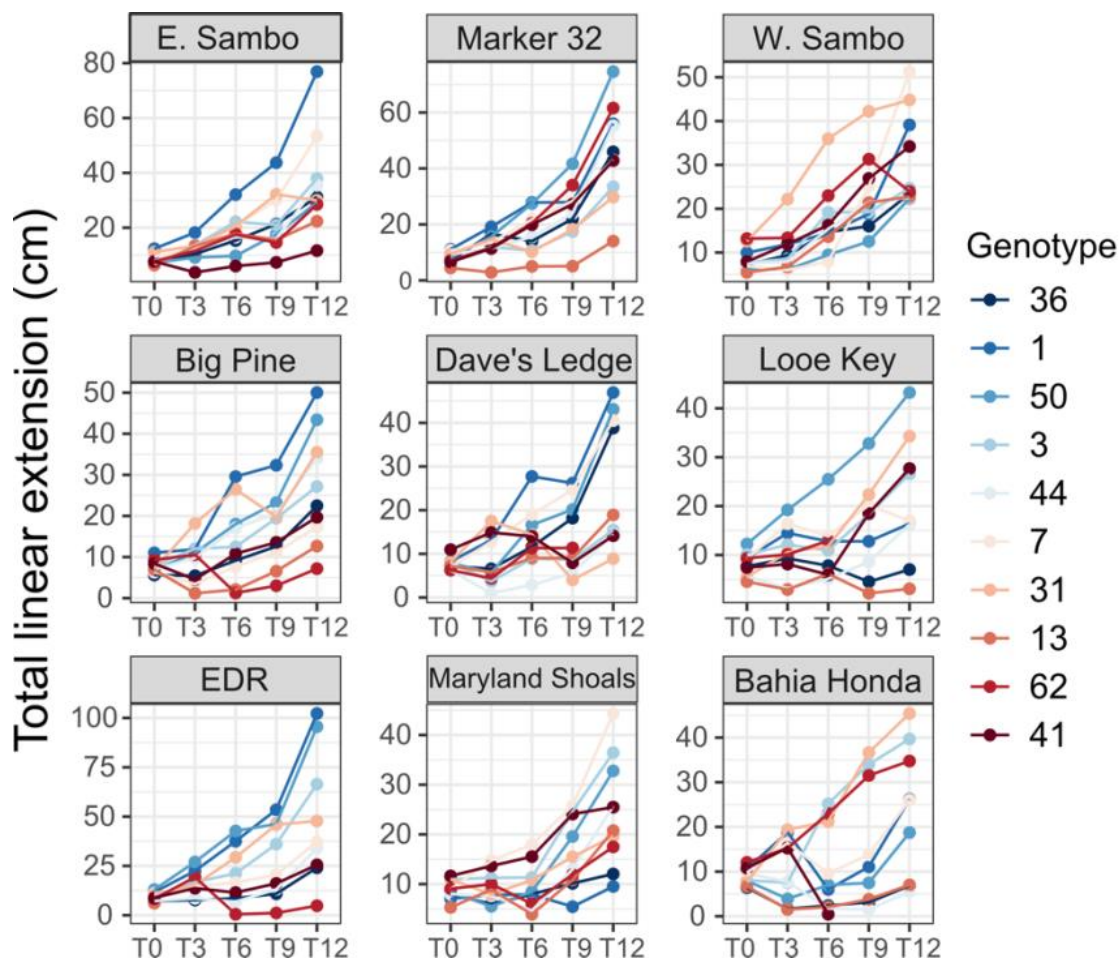

Figure 3: Average size in total linear extension (TLE) for each genotype (colored by survival probability as in Fig. 2A) over time. Reef sites are also ordered by survival probability (left to right).

Morphology exhibits plasticity that varies by genotype (GxE)

We assessed the fixed effects of genotype, outplant site, time, their interactions, as well as initial size on the absolute size in four traits: total linear extension (TLE), surface area (SA), volume $(\mathrm{V})$, and volume of interstitial space $\left(\mathrm{V}_{\text {inter }}\right)$ (Table $\mathrm{S6}$ ). Ramets experiencing fragmentation were retained, and the site-specific array to which the ramet was outplanted and the number of fragmentation events it experienced were included as random effects (Table S7). Significant genotype-by-site interactions were detected in all four traits $(\mathrm{p}<0.001)$, whereas no effects were detected for the genotype-by-time and genotype-by-site-by-time interactions in any trait $(\mathrm{p}>0.05)$. Absolute size trajectories varied among genets and inconsistent genet rank order was evident across 
sites, confirming the existence of GxE (Fig. 3, Fig. S3-5). Significant effects of genotype, time, and initial ramet size were also evident for all traits $(\mathrm{p}<0.0001)$. Absolute trait size increased over time and with the initial size of a ramet (Fig. 3, S3-5). Ramets of G50 were the largest on average, while G13's ramets were the smallest. The largest ramet sizes were reached at EDR, a site with the third worst survival on average (Fig. 2B). However, significant fixed effects of outplant site were not evident, while significant site-by-time interactions were found in SA and V ( $<<0.01)$. Random effects of fragmentation $(\mathrm{p}<0.0001)$ and array within site $(\mathrm{p}<0.0001)$ were also evident in all trait models (Table S7).

\section{Growth rate is dependent on genotypic and environmental characteristics}

Growth rate (unit/month) in each trait (TLE, SA, V, $\mathrm{V}_{\text {inter }}$ ), was modeled as a fixed effect of genotype, outplant site, time, and their interactions. Size at the beginning of each time interval was included as a fixed effect in linear mixed models to account for potential size-specific growth rates (Table S8). To accurately quantify growth rate, time periods where a ramet experienced negative growth due to fragmentation were excluded from the mixed models, following (33). Fragmentation and the site-specific array to which the ramet was outplanted were included as random effects (Table S9) and despite being removed from the analysis, a moderate effect of breakage persisted for $\mathrm{V}(\mathrm{p}=0.11)$. Genotype-by-site and the 3-way interaction between genotype, site, and time were not significant for the growth rate of any traits despite the significant GxE in absolute size. Significant genotype-by-time and site-by-time interactions were detected in TLE, $\mathrm{SA}, \mathrm{V}_{\text {inter }}(\mathrm{p}<0.01)$ and TLE, $\mathrm{V}$, and $\mathrm{V}_{\text {inter }}(\mathrm{p}<0.01)$, respectively. A significant fixed effect of genotype was present in TLE, $\mathrm{V}$, and $\mathrm{V}_{\text {inter }}(\mathrm{p}<0.05)$. Growth rate in all traits exhibited a significant fixed effect of time $(\mathrm{p}<0.0001)$. Growth rate increased with increasing initial size and time in all traits ( $<<0.0001$, Fig. S6) but standardized growth, calculated as growth rate per unit of existing tissue following (57), decreased with size (Fig. S7). Fixed effects of outplant site were only evident in $\mathrm{V}(\mathrm{p}=0.03)$ while variation among arrays within sites was nonsignificant in $\mathrm{V}$ and SA despite significant array effects on TLE and $\mathrm{V}_{\text {inter }}(\mathrm{p}<0.05)$.

\section{The capacity for morphological plasticity is correlated with improved survival and growth}

Genotype-by-site interactions in the absolute size of all traits indicates significant variation in the capacity for morphological plasticity among genets. We quantified plasticity using a joint regression analysis (58) which integrates trait data across multiple sites to provide a genotypespecific value of plasticity relative to the population. We found consistent correlations between the degree of trait plasticity, overall mortality risk, and mean growth rate that support an adaptive role (Fig. 4A). Plasticity in absolute size in TLE, SA, V, and $\mathrm{V}_{\text {inter }}$ was only weakly associated with mortality risk at $\mathrm{T} 3$ ( $\mathrm{R}=-0.33$ to $0.14, \mathrm{p}=0.14$ to 0.87 , Fig. S8). However, negative relationships, indicating reduced mortality risk in more plastic genotypes, strengthened over time with significant relationships in SA and V evident after 9 months $(R=-0.65, p=0.042$ and $R=-0.82, p=0.004$, respectively), and in TLE, $\mathrm{SA}$, and $\mathrm{V}$ after 12 months $(\mathrm{R}=-0.69, \mathrm{p}=0.029 ; \mathrm{R}=-0.71, \mathrm{p}=0.02$; and $\mathrm{R}=-0.67, \mathrm{p}=0.033$; Fig. S8). Similarly, relationships between average growth rate and trait plasticity began as neutral/weakly positive and progressed to strong positive correlations over time, with the strongest correlations found after 12 months $(R=0.81$ to $0.85, p=0.0019$ to 0.0043 , Fig. S9). Growth rate tended to be negatively correlated with mortality risk, indicating that higher growth rates were associated with decreased mortality risk, although significant relationships were only observed at later time points ( $\mathrm{V}, 9$ months, $\mathrm{R}=-0.7$, $\mathrm{p}=0.023$; TLE, $12 \mathrm{mos}, \mathrm{R}=-0.66, \mathrm{p}=0.037$; SA, 12 mos, R=-0.66, p=0.039, Fig. S10). 

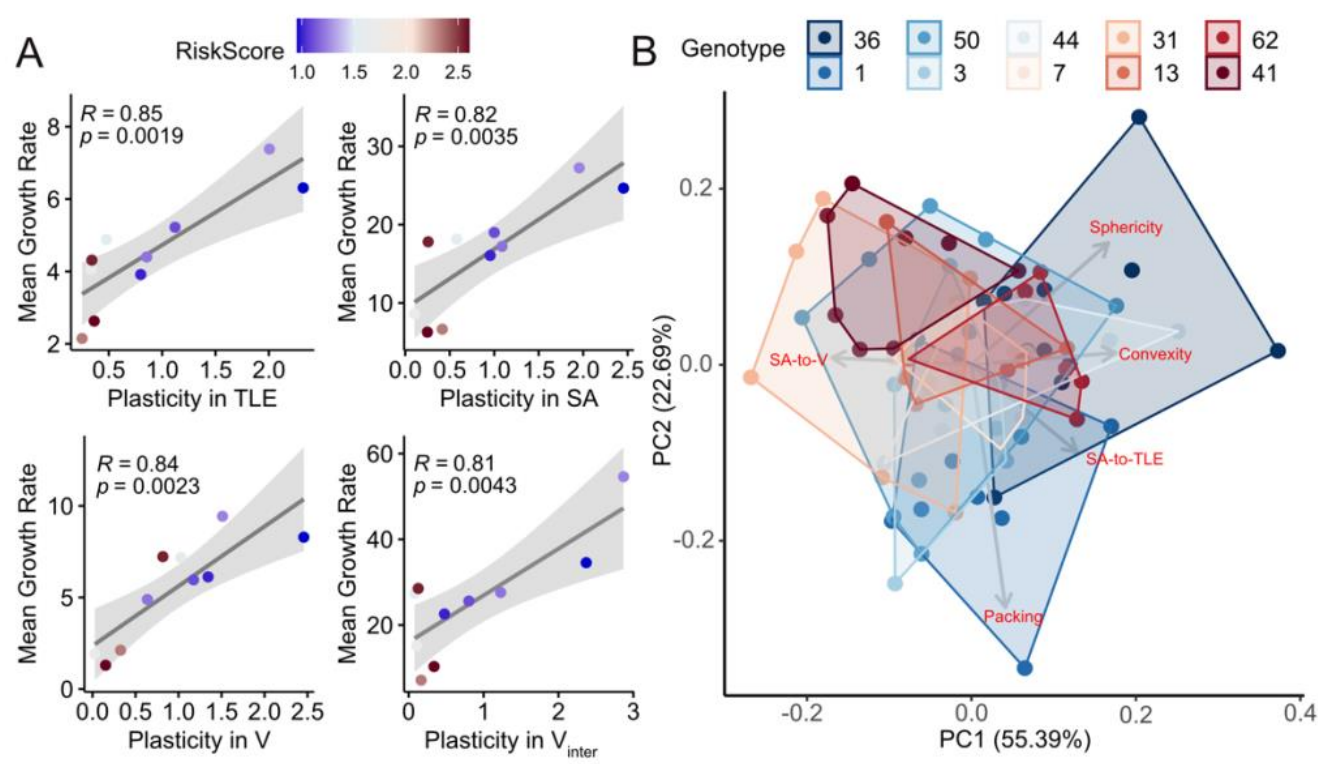

Figure 4. Morphological plasticity and its relationship to growth and survival. A) Relationship between genet plasticity in absolute size and average genet growth rate over the final 3 months of the outplant period. Points are colored by genet mortality risk score. Line and shaded region show line of best fit and 95\% confidence interval for each relationship. B) Principal components analysis of size-independent morphological traits: sphericity, convexity, packing (59), and SA-to-V ratio and SA-to-TLE ratio (gray vectors labeled in red). Points represent individual ramets colored by genet identity ( $\mathrm{n}=5-12$ ramets per genet) by decreasing survival from blue to red. Shaded regions (colored by survival rank) frame the most extraneous ramets for each genet and outline the morphospace occupied by a genet.

As a way to assess changes in colony shape regardless of size, we calculated SA-to- $V$ ratio, TLE-to-V ratio, packing, convexity, and sphericity (59) for ramets surviving to T12 with no fragmentation. This subset represents ramets occupying a morpho-space enabling survival and growth uninterrupted by breakage. When plotted in multivariate trait space, ramets did not cluster by genet or site (Fig. 4B, S11). However, ramets of genets showing higher average survival occupy a broader area, or trait space, compared to genets with lower survival (Fig. 4B).

\section{Variation among offshore reefs may contribute to site-specific growth and survival}

Benthic temperatures were recorded hourly at all sites for the one-year experimental period except for Looe Key where data from April 2018 to October 2018 are missing due to a flooded logger (Fig. S12). Therefore, the temperature profiles of 8 sites were used to analyze thermal differences among reefs. Water temperatures over the experimental period were similar between sites (Fig. 1D, Table S10). Annual mean temperatures varied by $0.213^{\circ} \mathrm{C}$ between the warmest (EDR) and coolest (Bahia Honda) sites. Annual temperature ranges varied from $10.12^{\circ} \mathrm{C}(\mathrm{E}$. Sambo) to $12.26^{\circ} \mathrm{C}$ (Bahia Honda) while average daily temperature ranges varied from $0.59^{\circ} \mathrm{C}$ (Marker 32) to $0.71^{\circ} \mathrm{C}$ (Bahia Honda). Big Pine experienced the most days where the temperature was at or above $30.5^{\circ} \mathrm{C}$ (69) while Bahia Honda experienced the fewest (54). Interestingly, Big Pine and Bahia Honda both had the most days above $32^{\circ} \mathrm{C} \mathrm{(3)} \mathrm{while} \mathrm{the} \mathrm{majority} \mathrm{of} \mathrm{sites} \mathrm{never}$ reached this temperature throughout the entire experimental period. Summer thermal predictability, calculated as the sum of positive temporal autocorrelation from July through September, was 
highest at W. Sambo and lowest at Bahia Honda. The three sites with the highest survival probability had the three highest thermal predictability values.

Site-specific biogeochemical parameters, obtained from the long-term SERC water quality monitoring program (56), did not differ when restricting the dataset to the experimental period. However, analysis of the full historical dataset (1995-2019) revealed significant differences in nitrate and silica dioxide concentrations among the 9 reef sites $(\mathrm{p}<0.05$, Fig S11). A principal components analysis of all thermal and water quality parameters showed large aggregate differences between sites despite this limited variation in individual parameters (Fig. 1E, S13, S14). Sites with the highest survival (E. Sambo, Marker 32, and W. Sambo) clustered together while the remaining sites were broadly distributed. These high survival sites were also associated with high thermal predictability and historical high average light attenuation (Fig. S14). Bahia Honda, the site with the lowest survival and growth, consistently stood out as the most extreme point (Fig. 1E, S13, S14).

After removing highly correlated water quality metrics, eleven parameters were used as candidate variables in a Bayesian negative binomial generalized linear model to assess their power to predict changes in coral morphology and mortality risk. Average temperature was significantly negatively associated with the change in TLE, SA, V, and $V_{\text {inter }}$ (Fig. 1F, Fig. S15-18) while average

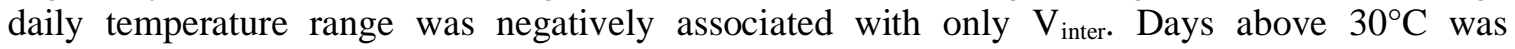
significantly positively associated with change in $\mathrm{V}_{\text {inter }}$ but no patterns were evident for other traits (Fig. S15-18). Risk score was not significantly associated with any of the environmental parameters (Fig. S19).

\section{Discussion}

The presence of a significant GxE interaction indicates that individuals differ in their sensitivity to environmental variation. This variation in reaction norm slope among individuals can reduce prediction accuracy and confound selective breeding programs (60). Here, we identify significant $\mathrm{GxE}$ in both the size and ultimate survival of restoration lines of A. cervicornis indicating that no single genet 'wins' in all contexts when considering the change in mean trait values across environments. However, the existence of $\mathrm{GxE}$ also means that there is genetic variation in the capacity for plasticity, or the degree of environmental responsiveness of individual genotypes. Rather than mean size, we find that this plasticity, or the degree to which a genet is able to change its size relative to the population mean across sites, is positively correlated with mean growth rate and survival. This suggests that plasticity may continue to evolve, although context-dependent trade-offs and the capacity to predict environmental variation will likely influence the ultimate trajectory. Below we consider potential drivers and implications of this adaptive plasticity for eco-evolutionary dynamics as well as its applied relevance for the conservation and restoration of reefs.

\section{Adaptive phenotypic plasticity in coral}

Phenotypic plasticity can facilitate acclimation over space and time by allowing organisms to match local phenotypic optima $(6,61)$. In reef-building corals, plastic responses in morphology $(44,62)$, bleaching (43), gene expression (52), and gene body methylation (63) alter colony phenotype in ways that are hypothesized to be beneficial, especially in the context of a stress response. In the absence of other performance data, however, it was unclear whether such individual plasticity would result in a net fitness benefit, particularly if significant costs were incurred by plastic individuals in non-stress contexts. Here, by explicitly linking morphological plasticity with growth and survival we show that an individual's ability to be plastic yields a net positive fitness outcome in A. cervicornis. Specifically, increased plasticity was associated with 
both a higher average growth rate and an increased probability of survival (decreased mortality risk, Fig. 4A) strongly supporting an adaptive role.

Coral morphology is an important environmental interface as changes in size and shape can adjust the flow, temperature, and $\mathrm{pH}$ in and around a colony $(64,65)$ affecting both normal processes, such as nutrient uptake, as well as responses to thermal or acidification stress (66-68). In the Florida Keys, spatially or temporally variable conditions, such as temperature, select for local phenotypic optima $(69,70)$ that appear to promote the overall persistence of plastic $A$. cervicornis genotypes. Although sites did not appear to select for specific morphologies in terms of their clustering patterns, genets with the highest average survival occupied a broader morphospace (Fig. 4B), again supporting an adaptive role for morphological plasticity.

Coral meet many of the conditions predicted to favor the evolution of increased plasticity (14). Long generation times and high habitat heterogeneity across dispersal ranges expand the range of environments individuals experience within their lifetime (71, 72). Assuming a genetic basis to plasticity, positive selection in the form of increased survival and/or reproduction of more plastic individuals can enable genetic accommodation, making future generations more plastic (6). This evolution of plasticity may be modulated by strong selection events occurring in $A$. cervicornis and other reef building coral in the form of disease or bleaching events $(40,73)$, although the magnitude and direction of the effects will depend on the relationship between morphological plasticity and the response to stress. We did not detect any tradeoffs between plasticity, growth rate and survival in ambient conditions, but exploring additional costs or limits to morphological plasticity will be an important next step in understanding the future adaptive potential of plasticity, particularly in the face of new environmental extremes. Warming ocean temperatures are an ever-present threat to coral reefs and tradeoffs between plasticity and bleaching tolerance or recovery would severely limit the benefits of morphological plasticity as bleaching events become more frequent and severe $(39,40)$.

\section{Genotype-environment interactions limit survival and growth predictions}

Survival and growth are two metrics commonly used to evaluate coral fitness because improved survival will positively impact population demographic rates (74-76) while faster growth can shorten the time to reproductive maturity (77). Although lifetime reproductive success is difficult to measure in annual broadcast spawning species such as coral, greater reproductive capacity has been observed in larger colonies (77). Significant variation in the Cox Proportional Hazard risk scores indicated that some genotypes (G41, G62, G13) were at greater risk of mortality than others. Similarly, reef sites also varied in their ability to support coral survival. These results align with previous findings of strong genotype and site effects on coral survival $(32,57)$ and suggest that certain genets (G36) and reef sites (E. Sambo) may be higher quality overall. When looking at the remaining genets and sites, however, genotype-by-site interactions for survival and lack of preservation in the rank order of genet survivorship between reef sites (Fig. 2C) indicate a limited ability to predict outcomes based on knowledge of genotypes or sites in isolation. This stands in contrast to a similar in situ transplant experiment by Drury et al. (33) that found site effects but no effect of genotype or the interaction on mortality. However, corals in this prior study endured a thermal bleaching event and variation in mortality was attributed to variation in bleaching among reef sites (33). While no bleaching was observed during the course of our experiment, our results indicate that under normal conditions, genet survivorship from a single site alone does not predict survival in other, even geographically neighboring, reefs.

Similarly, coral morphology appears to be influenced by a complex set of interacting factors that ultimately preclude identification of a globally top performing individual or 'super coral' (34). Genotype-by-site interactions were evident in absolute size which resulted in a different collection of genets representing the largest relative coral at each site after the 12 month 
402

outplant period (Fig. 3). This is the first evidence of GxE in A. cervicornis morphology, although this finding builds on earlier work in other branching coral species $(53,54,78)$. It is important to note that statistical models included corals that experienced fragmentation, as this is an ecologically relevant phenomenon contributing to clonal reproduction (79). When we excluded fragmentation, significant genotype-by-site interactions disappeared. Similarly, (33) excluded negative growth and showed independent impacts of genotype and environment on TLE in $A$. cervicornis, but no GxE was detected. Significant fixed effects of genotype on both absolute size and growth rate for TLE, SA, V, and $\mathrm{V}_{\text {inter }}$ suggest that the intrinsic growth rate does vary among genets. However, this capacity may be limited by fragmentation, which also varies as a function of genotype and site. Ultimately however, population demographic and restoration success are based on size of coral colonies rather than their growth rate, indicating that GxE must be accounted for when developing conservation and restoration strategies.

Unlike earlier studies in both A. cervicornis (33) and its sister species, A. palmata (80), we find no effect of site on the majority of morphological and growth traits despite strong site effects on survival. Once thought of as noise, GxE allows for the presence of phenotypic variation among individuals in the absence of overall site effects and may provide a proximate explanation for their absence here. Alternatively, differences in experimental design may also play a role. Kuffer et al. (80) compared ramets outplanted over a large spatial scale (>300 km) compared to the $\sim 60 \mathrm{~km}$ span covered in the present study. Similarly, Drury et al. (33) selected reef sites spanning inshore and offshore zones. Although reefs within the offshore zone vary in environmental conditions (56) larger differences are evident between inshore and offshore reefs in temperature, turbidity, and nutrients $(56,81)$ may have driven the pronounced site effects on morphology reported earlier (33). Finally, temporal variability in environmental stress can create periods of poor growth or high fragmentation followed by periods of recovery that may mask mean site effects and instead generate a site-by-time signal. We did observe significant site-bytime effects on the majority of morphological traits indicating that site effects are likely to be time dependent.

\section{The importance of fragmentation}

Fragmentation is a vital part of the evolutionary ecology of A. cervicornis as it can significantly alter the demographic trajectory of populations through asexual propagation (79, 82), partial mortality, or death (83). In this experiment numerous instances of breakage had obvious negative impacts on colony size but were mostly nonfatal. This suggests that fragmentation can also impact growth beyond the immediate response to injury, such as increased productivity due to size-dependent growth rates that occur after size reduction (57). While sometimes considered random, fragmentation in this study occurred significantly more in some genets and sites. Differences in calcification rate among A. cervicornis genets $(84,85)$ mean that certain individuals can produce more dense skeletons faster, potentially making them less prone to breakage. Moreover, calcification is energetically expensive (86) and apparent trade-offs in skeletal density and colony size $(84,85)$ suggest different strategies for skeletal growth in this species that may lead to variation in the ability to withstand physical stress leading to breakage.

Spatial and temporal variation in hydrodynamic energy $(87,88)$, likely also imposes variable mechanical stress on coral colonies. Coral morphology may respond to these conditions $(44,89)$, but sudden or especially strong hydrodynamic forces are common sources of damage for branching corals in the Caribbean $(90,91)$. Human activity may also have contributed to fragmentation and anecdotally, higher tourist activity was observed at Looe Key and EDR. Although fragmentation was usually nonfatal in the focal ramet, we did not track the fate of newly generated fragments precluding determination of the ultimate effect on fitness. Regardless, the existence of non-random fragmentation reinforces the notion that accounting for 
fragmentation, rather than treating it as experimental error, will be important for accurately predicting changes in branching coral morphology and performance.

\section{Multivariate environmental conditions distinguish reefs}

The offshore reef sites used here are in an area that has historically been treated as a single environmental unit (56). However, site specific variation in coral performance (Fig. 2B, Fig. 3) and in environmental condition (Fig. 1E) support the need for a more nuanced approach. Aggregate differences in abiotic conditions among sites with high average survival appear to be defined by high nitrogen concentrations, thermal predictability, light attenuation/turbidity, and low annual and average daily temperature ranges (Fig. S13-14). Similarly, the site with the lowest average survival, Bahia Honda, differentiated by historically high ranges of nitrite and total phosphorus concentrations, turbidity, and light attenuation (Fig. S14). This site also had the highest annual and daily temperature ranges, but lowest summer thermal predictability during the experimental period. Although no physical or chemical condition was individually correlated with mortality in the Bayesian models, fluctuating environmental conditions have been implicated in the conditioning of marine species to climate change $(92,93)$. While temperature variability can enhance coral tolerance $(94,95)$, the predictability of those fluctuations should also impact the ability to acclimate and adapt $(96,97)$. Thermal predictability was highest among the three sites with the highest survival (E. Sambo, Marker 32, and W. Sambo) and lowest at Bahia Honda yet no correlations were detected, suggesting the importance of a multivariate approach. The low temporal resolution of water quality metrics precluded obtaining similar measures of predictability in water chemistry during the experimental period. Future work quantifying environmental predictability in addition to fluctuations may yield additional insight into the conditions that support coral performance and plasticity.

Mean temperature was negatively associated with change in size of all morphological traits (Fig. 1F, S15-18), suggesting that cooler conditions promoted ramet growth. This is unsurprising considering the well documented negative impact of high temperatures on coral performance (98) and the fact that mean experimental temperatures were within or above the apparent optimum thermal range (ca $25-29^{\circ} \mathrm{C}$ ) for A. cervicornis $(99,100)$. Interestingly, the number of days above $30.5^{\circ} \mathrm{C}$ seemed to encourage growth in $\mathrm{V}_{\text {inter }}$ but no other trait. Morphology has been shown to impact flow around a colony, altering heat flux at the coral surface $(64,68)$ with branching morphologies more capable of offloading heat compared to mounding coral (101). As A. cervicornis ramets become less compact by increasing the volume of their interstitial space (Fig. 1C), heat dissipation at the coral surface can also be expected to increase through a reduction in the thermal boundary layer $(68,101)$. While the offshore reef tract of the Florida Keys is typically considered environmentally contiguous, taken together these results suggest spatial variation in reef conditions independently and cumulatively shape coral performance.

\section{Conclusions}

Current coral restoration strategies rely on transplanting clones across reefs varying in abiotic and biotic conditions $(33,37,55)$ suggesting that plasticity will play a role in the success or failure of individual colonies. Adaptive morphological plasticity in A. cervicornis may enable genets to maintain fitness in response to changes in environmental conditions over time or space. Continued positive selection on intraspecific variation in plasticity, contingent on its freedom from tradeoffs, should promote the evolution of plasticity and therefore the acclimatory benefits associated with it. Environmental conditions can also promote or constrain the evolution of phenotypic plasticity $(10,96)$ and while there appears to be sufficient variation within the $A$. cervicornis habitat range to induce plasticity at present, its relative benefits will likely also be 
dependent on the ability to predict environmental fluctuations, which may prove challenging in the face of continued climate change.

\section{Materials and Methods}

\section{Experimental design}

Ten coral genets maintained long-term (5+ years) at Mote Marine Laboratory's in situ coral nursery (Table S10) were outplanted in a multi-site transplant study under FKMNS permits 2015-163-A1 and 2018-035. In April 2018, 270 coral (mean TLE of $8.4 \mathrm{~cm}$ ) ramets representing 10 genets ( 27 ramets per genet) affixed to concrete pucks were photographed following Million et al. (102) and manually measured for TLE immediately before transplantation to nine active restoration sites (Table S1, Fig. 1). Three ramets per genet ( $\mathrm{n}=270$ fragments) were randomly outplanted at each site with one ramet allocated to each of three ten-coral arrays (Fig. 1A). Coral pucks were attached to bare reef substrate using marine epoxy over 4 days, from April 21 to April 25.

Outplant sites were resurveyed in July 2018, October 2018, January 2019, and April 2019. Ramets were individually re-photographed and measured by-hand at the first four timepoints for TLE. Survivorship was recorded during site surveys and later confirmed with photographs. Breakage was recorded via the photographic time series and through negative growth measures in the resulting trait dataset (Supplemental Methods). Ramets where both the coral tissue and ceramic puck were missing indicated technical failure of the marine epoxy rather than a true biological loss and were excluded from subsequent analyses.

\section{Phenotyping}

Photographs taken in situ were used to generate individual 3D models of each coral ramet in Metashape 1.5.4 (Agisoft LLC, St. Petersburg, Russia) using a high-throughput pipeline (102). Specifications for model building and all scripts can be found at https://github.com/wyattmillion/Coral3DPhotogram. 3D models were imported into Meshlab v2020.6 (103) to measure four growth-related traits following protocols described in Million et al. (102) and detailed in the Supplementary Methods: TLE, SA, V, and $\mathrm{V}_{\text {inter. }}$ We assessed the final shape of colonies that survived to T12 with no detectable fragmentation by calculating SA-to-V and TLE-to-V ratios, in addition to packing, convexity, and sphericity (59). Among this subset, genets were more equally represented ( $n=5-12$ ramets per genets) than sites ( $n=2-18$ ramets per site). These traits were used in a principal components analysis to determine how ramets clustered in morphospace as a function of genet and site.

\section{Environmental data}

All reef sites are located along the offshore reef tract of the Lower Florida Keys at a depth of 5.6m to 9.1m. HOBO Pendant Temperature loggers (Onset Computer Corp.; Bourne, MA), set to record hourly, were attached to the reef substrate directly adjacent to the outplanted corals, and exchanged with new loggers on subsequent site visits. Hourly temperature records were used to calculate annual mean, annual range, average daily range, maximum monthly mean, days and hours above $30.5^{\circ} \mathrm{C}$ or $32^{\circ} \mathrm{C}$, and summer thermal predictability. Thermal predictability was quantified for July through September only as highly variable temperatures at or above the bleaching threshold of $30.5^{\circ} \mathrm{C}$ are expected during this window (104). Predictability was calculated as the sum of autocorrelation over a series of lags until autocorrelation reached zero, i.e. the point at which current temperatures are no longer informative of future conditions (105, 106). Quarterly concentrations of benthic nitrite, nitrate, ammonia, dissolved organic and inorganic nitrogen, soluble reactive phosphorus, total phosphorus, total nitrogen, N:P ratio, 
500

501

502

503

504

505

506

507

508

509

510

511

512

513

514

515

516

517

518

519

520

521

522

523

524

525

526

silicate, dissolved oxygen, total organic carbon, as well as turbidity and light attenuation for each outplant site were obtained from the Southeast Environmental Research Center (SERC) water quality dataset (Florida International University) associated with each site (Fig. 1A, serc.fiu.edu/wqmnetwork/FKNMS-CD/DataDL.htm).

\section{Statistical analysis}

All statistical analyses were performed in R version 3.6.3 (107) and scripts can be found at github.com/wyattmillion/Acer_Morphological_Plasticity. Cox Proportional Hazard models were fitted to outplant survival data using the coxme (108) and survival (109) packages. Consistency in genet rank order across sites was quantified with Pearson's correlations. Cumulative Linked Mixed Models assessing the ordinal response of fragmentation were implemented with the package ordinal (110) to test for effects of genotype and outplant site on cumulative breakage events summed within a ramet over time. Fisher Exact Tests were used to determine enrichment of fragmentation among A. cervicornis size classes.

Effects of genotype, site, time, all associated interactions, and initial size on colony morphology ( $\sim$ size) and growth rate in TLE, SA, V, and $\mathrm{V}_{\text {inter }}$ were tested with linear mixed effects models implemented with the package lmer (111). Fragmentation and outplant array nested within-site were included as random effects. When calculating growth rate, ramets experiencing fragmentation (evidenced by a negative growth rate for a ramet over a 3-month interval) were removed from the dataset and replaced with NA for the time-point in which fragmentation occurred.

The extent of plasticity was quantified across each time interval using the joint regression framework $(58,112,113)$ where genet mean sizes at each site were regressed against the sitewide mean. Regression coefficients representing plasticity in TLE, SA, V, and $\mathrm{V}_{\text {inter }}$ were correlated with Cox mortality risk scores and average genet growth rates using Pearson Correlations.

SERC water quality parameters and thermal characteristics were used to describe environmental variation among reef sites. We calculated both the overall mean and the range of benthic nutrient concentrations, turbidity, and light attenuation over the entire length of the SERC dataset (Spring 1995 to Spring 2019) and over the experimental period (April 2018 to 2019). The historical and contemporary SERC data were used to identify differences between reef sites along with high resolution temperature data collected during the experimental period. An analysis of variance was used to identify significant differences among sites for independent parameters. A principal components analysis was used to explain variation among sites using all parameters simultaneously.

Bayesian negative binomial generalized linear models implemented in R2jags (114) were used to test for the impact of environmental parameters on the growth and survival of ramets at reef sites. Model power was improved by using size, risk score, and environmental data over each of the four time intervals to increase sample size and by removing highly correlated environmental variables.

\section{Acknowledgements}

We are grateful to Yingqi Zhang, Hunter Ramo, Cory Walter, and Joseph Kuehl for their help photographing coral in situ. Eric Million helped design and build equipment for in situ 3D photogrammetry. Phoebe Chang contributed to image preprocessing and Alexandra Stella and Aryana Volk helped with model validation. Elaina Graham generously facilitated access to the Heidelberg Lab high performance computer. Training in Bayesian analyses from Dr. Robert van Woesik was facilitated by the NSF Coral Bleaching RCN Early Career Training Program. Figure 
1 was created with BioRender.com. All fieldwork was conducted under permits FKNMS-2015163-A1 and FKNMS-2018-035.

\section{Author Contributions}

CDK and CJK designed the experiment and obtained funding; WCM, MR, EB, CJK and CDK conducted the experiment; All authors collected data; WCM and CDK performed data analysis; WCM and CDK wrote the initial manuscript while all authors revised and contributed to the final version.

\section{Conflict of Interest}

The authors declare no competing interest.

\section{Funding Information}

This research was supported by National Oceanic and Atmospheric Administration Coral Reef Conservation Program grant NA17NOS4820084 and private funding from the Alfred P. Sloan and Rose Hills Foundations.

\section{Data Accessibility}

The datasets and scripts used in this study can be found at https://github.com/ wyattmillion/Acer_Morphological_Plasticity.

\section{References}

1. S. Des Roches, L. H. Pendleton, B. Shapiro, E. P. Palkovacs, Conserving intraspecific variation for nature's contributions to people. Nat Ecol Evol 5, 574-582 (2021).

2. M. J. West-Eberhard, Developmental Plasticity and Evolution (Oxford University Press, 2003).

3. G. G. Simpson, The Baldwin Effect. Evolution 7, 110-117 (1953).

4. M. J. West-Eberhard, Phenotypic Plasticity and the Origins of Diversity. Annu. Rev. Ecol. Syst. 20, 249-278 (1989).

5. J. B. Losos, et al., Evolutionary implications of phenotypic plasticity in the hindlimb of the lizard Anolis sagrei. Evolution 54, 301-305 (2000).

6. M. Kelly, Adaptation to climate change through genetic accommodation and assimilation of plastic phenotypes. Philos. Trans. R. Soc. Lond. B Biol. Sci. 374, 20180176 (2019).

7. C. K. Ghalambor, J. K. McKAY, S. P. Carroll, D. N. Reznick, Adaptive versus non-adaptive phenotypic plasticity and the potential for contemporary adaptation in new environments. Funct. Ecol. 21, 394-407 (2007).

8. A. P. Moczek, et al., The role of developmental plasticity in evolutionary innovation. Proc. Biol. Sci. 278, 2705-2713 (2011).

9. Y. Suzuki, H. F. Nijhout, Evolution of a polyphenism by genetic accommodation. Science 311, 650-652 (2006). 
10. S. Gavrilets, S. M. Scheiner, The genetics of phenotypic plasticity. V. Evolution of reaction norm shape. J. Evol. Biol. 6, 31-48 (1993).

11. S. M. Scheiner, Genetics and Evolution of Phenotypic Plasticity. Annual review of ecology and systematics 24, 35-68 (1993).

12. M. Pigliucci, Evolution of phenotypic plasticity: where are we going now? Trends Ecol. Evol. 20, 481-486 (2005).

13. T. J. Dewitt, A. Sih, D. S. Wilson, Costs and limits of phenotypic plasticity. Trends Ecol. Evol. 13, 77-81 (1998).

14. A. P. Hendry, Key Questions on the Role of Phenotypic Plasticity in Eco-Evolutionary Dynamics. J. Hered. 107, 25-41 (2016).

15. J. Van Buskirk, U. K. Steiner, The fitness costs of developmental canalization and plasticity. J. Evol. Biol. 22, 852-860 (2009).

16. J. P. Velotta, Z. A. Cheviron, Remodeling Ancestral Phenotypic Plasticity in Local Adaptation: A New Framework to Explore the Role of Genetic Compensation in the Evolution of Homeostasis. Integr. Comp. Biol. 58, 1098-1110 (2018).

17. M. L. Reaka-Kudla, D. E. Wilson, E. O. Wilson, Biodiversity II: Understanding and Protecting Our Biological Resources (Joseph Henry Press, 1996).

18. N. Knowlton, et al., "Coral reef biodiversity" in Life in the World's Oceans: Diversity, Distribution, and Abundance, A. McIntyre, Ed. (John Wiley \& Sons, 2010), pp 65-74.

19. N. A. J. Graham, K. L. Nash, The importance of structural complexity in coral reef ecosystems. Coral Reefs 32, 315-326 (2013).

20. S. G. Monismith, Hydrodynamics of Coral Reefs. Annu. Rev. Fluid Mech. 39, 37-55 (2007).

21. A. Lugo-Fernández, H. H. Roberts, Wiseman, Jr, W. J., Tide Effects on Wave Attenuation and Wave Set-up on a Caribbean Coral Reef. Estuar. Coast. Shelf Sci. 47, 385-393 (1998).

22. D. J. Coker, S. K. Wilson, M. S. Pratchett, Importance of live coral habitat for reef fishes. Rev. Fish Biol. Fish. 24, 89-126 (2014).

23. A. M. Szmant, Nutrient effects on coral reefs: a hypothesis on the importance of topographic and trophic complexity to reef nutrient dynamics in Proc 8th Int Coral Reef Symp, (1997), pp. 1527-1532.

24. H. Cesar, L. Burke, A. L. Pet-Soede, The economics of worldwide coral reef degradation. International Coral Reef Action Network (2003).

25. M. S. Pratchett, A. S. Hoey, S. K. Wilson, Reef degradation and the loss of critical ecosystem goods and services provided by coral reef fishes. Current Opinion in Environmental Sustainability 7, 37-43 (2014). 
623

624

625

626

627

628

629

630

631

632

26. J. W. Porter, O. W. Meier, Quantification of Loss and Change in Floridian Reef Coral Populations. Integr. Comp. Biol. 32, 625-640 (1992).

27. K. L. Cramer, et al., Widespread loss of Caribbean acroporid corals was underway before coral bleaching and disease outbreaks. Sci Adv 6, eaax9395 (2020).

28. G. Roff, J. Joseph, P. J. Mumby, Multi-decadal changes in structural complexity following mass coral mortality on a Caribbean reef. Biogeosciences 17, 5909-5918 (2020).

29. L. Alvarez-Filip, I. M. Côté, J. A. Gill, A. R. Watkinson, N. K. Dulvy, Region-wide temporal and spatial variation in Caribbean reef architecture: is coral cover the whole story? Glob. Chang. Biol. 17, 2470-2477 (2011).

30. P. J. Edmunds, Evidence that reef-wide patterns of coral bleaching may be the result of the distribution of bleaching-susceptible clones. Mar. Biol. 121, 137-142 (1994).

31. R. Cunning, et al., Census of heat tolerance among Florida's threatened staghorn corals finds resilient individuals throughout existing nursery populations. Proceedings of the Royal Society B: Biological Sciences 288, 20211613 (2021).

32. R. Woesik, et al., Differential survival of nursery-reared Acropora cervicornis outplants along the Florida reef tract. Restor. Ecol. 29 (2021).

33. C. Drury, D. Manzello, D. Lirman, Genotype and local environment dynamically influence growth, disturbance response and survivorship in the threatened coral, Acropora cervicornis. PLoS One 12, e0174000 (2017).

34. E. F. Camp, V. Schoepf, D. J. Suggett, How can "Super Corals" facilitate global coral reef survival under rapid environmental and climatic change? Glob. Chang. Biol. 24, 2755-2757 (2018).

35. S. R. Palumbi, D. J. Barshis, N. Traylor-Knowles, R. A. Bay, Mechanisms of reef coral resistance to future climate change. Science 344, 895-898 (2014).

36. M. O. Hoogenboom, et al., Environmental Drivers of Variation in Bleaching Severity of Acropora Species during an Extreme Thermal Anomaly. Frontiers in Marine Science 4 (2017).

37. C. N. Young, S. A. Schopmeyer, D. Lirman, A Review of Reef Restoration and Coral Propagation Using the Threatened Genus Acropora in the Caribbean and Western Atlantic. Bull. Mar. Sci. 88, 1075-1098 (2012).

38. O. Hoegh-Guldberg, et al., Assisted colonization and rapid climate change. Science 321, 345-346 (2008).

39. O. Hoegh-Guldberg, et al., Coral reefs under rapid climate change and ocean acidification. Science 318, 1737-1742 (2007).

40. D. P. Manzello, Rapid Recent Warming of Coral Reefs in the Florida Keys. Sci. Rep. 5, 16762 (2015). 
41. K. L. Barott, et al., Coral bleaching response is unaltered following acclimatization to reefs with distinct environmental conditions. Proc. Natl. Acad. Sci. U. S. A. 118 (2021).

42. M. K. Morikawa, S. R. Palumbi, Using naturally occurring climate resilient corals to construct bleaching-resistant nurseries. Proceedings of the National Academy of Sciences 116 (2019).

43. C. Drury, D. Lirman, Genotype by environment interactions in coral bleaching. Proc. Biol. Sci. 288, 20210177 (2021).

44. P. A. Todd, Morphological plasticity in scleractinian corals. Biol. Rev. Camb. Philos. Soc. 83, 315-337 (2008).

45. E. Tambutté, et al., Morphological plasticity of the coral skeleton under CO2-driven seawater acidification. Nat. Commun. 6, 7368 (2015).

46. E. M. Muller, et al., Heritable variation and lack of tradeoffs suggest adaptive capacity in Acropora cervicornis despite negative synergism under climate change scenarios. Proc. Biol. Sci. 288, 20210923 (2021).

47. M. Ziegler, C. M. Roder, C. Büchel, C. R. Voolstra, Limits to physiological plasticity of the coral Pocillopora verrucosa from the central Red Sea. Coral Reefs 33, 1115-1129 (2014).

48. R. A. Bay, S. R. Palumbi, Rapid Acclimation Ability Mediated by Transcriptome Changes in Reef-Building Corals. Genome Biol. Evol. 7, 1602-1612 (2015).

49. M. M. Rocker, C. D. Kenkel, D. S. Francis, B. L. Willis, L. K. Bay, Plasticity in gene expression and fatty acid profiles of Acropora tenuis reciprocally transplanted between two water quality regimes in the central Great Barrier Reef, Australia. J. Exp. Mar. Bio. Ecol. 511, 40-53 (2019).

50. M. O. Hoogenboom, S. R. Connolly, K. R. N. Anthony, Interactions between morphological and physiological plasticity optimize energy acquisition in corals. Ecology 89, 1144-1154 (2008).

51. A. G. Grottoli, L. J. Rodrigues, J. E. Palardy, Heterotrophic plasticity and resilience in bleached corals. Nature 440, 1186-1189 (2006).

52. C. D. Kenkel, M. V. Matz, Gene expression plasticity as a mechanism of coral adaptation to a variable environment. Nat Ecol Evol 1, 14 (2016).

53. J. F. Bruno, P. J. Edmunds, Clonal variation for phenotypic plasticity in the coralmadracis Mirabilis. Ecology 78, 2177-2190 (1997).

54. P. A. Todd, R. J. Ladle, N. J. I. Lewin-Koh, L. M. Chou, Genotype $\times$ environment interactions in transplanted clones of the massive corals Favia speciosa and Diploastrea heliopora. Mar. Ecol. Prog. Ser. 271, 167-182 (2004). 
55. K. E. Lohr, S. Bejarano, D. Lirman, S. Schopmeyer, C. Manfrino, Optimizing the productivity of a coral nursery focused on staghorn coral Acropora cervicornis. Endanger. Species Res. 27, 243-250 (2015).

56. H. O. Briceño, J. N. Boyer, 2018 Annual Report of the Water Quality Monitoring Project for the Water Quality Protection Program of the Florida Keys National Marine Sanctuary (2019).

57. D. Lirman, et al., Growth dynamics of the threatened Caribbean staghorn coral Acropora cervicornis: influence of host genotype, symbiont identity, colony size, and environmental setting. PLoS One 9, e107253 (2014).

58. J. R. Stinchcombe, L. A. Dorn, J. Schmitt, Flowering time plasticity in Arabidopsis thaliana: a reanalysis of Westerman \& Lawrence (1970). J. Evol. Biol. 17, 197-207 (2004).

59. K. J. A. Zawada, M. Dornelas, J. S. Madin, Quantifying coral morphology. Coral Reefs 38, 1281-1292 (2019).

60. D. Ly, et al., Relatedness and genotype $\mathrm{x}$ environment interaction affect prediction accuracies in genomic selection: a study in cassava. Crop Sci. (2013).

61. S. Via, et al., Adaptive phenotypic plasticity: consensus and controversy. Trends Ecol. Evol. 10, 212-217 (1995).

62. S. Muko, K. Kawasaki, K. Sakai, F. Takasu, N. Shigesada, Morphological plasticity in the coral Porites sillimaniani and its adaptive significance. Bull. Mar. Sci. 66, 225-239 (2000).

63. G. Dixon, Y. Liao, L. K. Bay, M. V. Matz, Role of gene body methylation in acclimatization and adaptation in a basal metazoan. Proc. Natl. Acad. Sci. U. S. A. 115, 13342-13346 (2018).

64. J. B. Stocking, C. Laforsch, R. Sigl, M. A. Reidenbach, The role of turbulent hydrodynamics and surface morphology on heat and mass transfer in corals. J. R. Soc. Interface 15, 20180448 (2018).

65. N. C. S. Chan, D. Wangpraseurt, M. Kühl, S. R. Connolly, Flow and Coral Morphology Control Coral Surface pH: Implications for the Effects of Ocean Acidification. Frontiers in Marine Science 3 (2016).

66. W. C. Dennison, D. J. Barnes, Effect of water motion on coral photosynthesis and calcification. J. Exp. Mar. Bio. Ecol. 115, 67-77 (1988).

67. M. P. Lesser, V. M. Weis, M. R. Patterson, P. L. Jokiel, Effects of morphology and water motion on carbon delivery and productivity in the reef coral, Pocillopora damicornis (Linnaeus): Diffusion barriers, inorganic carbon limitation, and biochemical plasticity. $J$. Exp. Mar. Bio. Ecol. 178, 153-179 (1994).

68. I. M. Jimenez, M. Kühl, A. W. D. Larkum, P. J. Ralph, Effects of flow and colony morphology on the thermal boundary layer of corals. J. R. Soc. Interface 8, 1785-1795 (2011). 
69. C. D. Kenkel, A. T. Almanza, M. V. Matz, Fine-scale environmental specialization of reefbuilding corals might be limiting reef recovery in the Florida Keys. Ecology 96, 3197-3212 (2015).

70. D. P. Manzello, et al., Role of host genetics and heat-tolerant algal symbionts in sustaining populations of the endangered coral Orbicella faveolata in the Florida Keys with ocean warming. Glob. Chang. Biol. 25, 1016-1031 (2019).

71. C. Drury, C. B. Paris, V. H. Kourafalou, D. Lirman, Dispersal capacity and genetic relatedness in Acropora cervicornis on the Florida Reef Tract. Coral Reefs 37, 585-596 (2018).

72. E. M. Hemond, S. V. Vollmer, Genetic diversity and connectivity in the threatened staghorn coral (Acropora cervicornis) in Florida. PLoS One 5, e8652 (2010).

73. D. E. Williams, M. W. Miller, Coral disease outbreak: pattern, prevalence and transmission in Acropora cervicornis. Marine Ecology Progress Series 301, 119-128 (2005).

74. R. C. Babcock, Comparative Demography of Three Species of Scleractinian Corals Using Age- and Size-Dependent Classifications. Ecological Monographs 61, 225-244 (1991).

75. T. P. Hughes, D. Ayre, J. H. Connell, The evolutionary ecology of corals. Trends Ecol. Evol. 7, 292-295 (1992).

76. M. Álvarez-Noriega, et al., Fecundity and the demographic strategies of coral morphologies. Ecology 97, 3485-3493 (2016).

77. V. R. Hall, T. P. Hughes, Reproductive strategies of modular organisms: Comparative studies of reef- building corals. Ecology 77, 950-963 (1996).

78. N. E. Doszpot, M. J. McWilliam, M. S. Pratchett, A. S. Hoey, W. F. Figueira, Plasticity in Three-Dimensional Geometry of Branching Corals Along a Cross-Shelf Gradient. Diversity 11, 44 (2019).

79. C. Drury, J. B. Greer, I. Baums, B. Gintert, D. Lirman, Clonal diversity impacts coral cover in Acropora cervicornisthickets: Potential relationships between density, growth, and polymorphisms. Ecol. Evol. 9, 4518-4531 (2019).

80. I. B. Kuffner, A. Stathakopoulos, L. T. Toth, L. A. Bartlett, Reestablishing a stepping-stone population of the threatened elkhorn coral Acropora palmata to aid regional recovery. Endanger. Species Res. 43, 461-473 (2020).

81. D. Lirman, P. Fong, Is proximity to land-based sources of coral stressors an appropriate measure of risk to coral reefs? An example from the Florida Reef Tract. Mar. Pollut. Bull. 54, 779-791 (2007).

82. V. Tunnicliffe, Breakage and propagation of the stony coral Acropora cervicornis. Proc. Natl. Acad. Sci. U. S. A. 78, 2427-2431 (1981). 
83. J. S. Madin, A. H. Baird, M. Dornelas, S. R. Connolly, Mechanical vulnerability explains size-dependent mortality of reef corals. Ecol. Lett. 17, 1008-1015 (2014).

84. I. B. Kuffner, et al., Plasticity in skeletal characteristics of nursery-raised staghorn coral, Acropora cervicornis. Coral Reefs 36, 679-684 (2017).

85. K. E. Lohr, J. T. Patterson, Intraspecific variation in phenotype among nursery-reared staghorn coral Acropora cervicornis (Lamarck, 1816). J. Exp. Mar. Bio. Ecol. 486, 87-92 (2017).

86. A. L. Cohen, T. A. McConnaughey, Geochemical Perspectives on Coral Mineralization. Rev. Mineral. Geochem. 54, 151-187 (2003).

87. J. J. Leichter, G. B. Deane, M. D. Stokes, Spatial and Temporal Variability of Internal Wave Forcing on a Coral Reef. J. Phys. Oceanogr. 35, 1945-1962 (2005).

88. S. Ahn, K. A. Haas, V. S. Neary, Dominant Wave Energy Systems and Conditional Wave Resource Characterization for Coastal Waters of the United States. Energies 13, 3041 (2020).

89. P. L. Jokiel, C. P. Jury, I. B. Kuffner, "Coral Calcification and Ocean Acidification" in Coral Reefs at the Crossroads, D. K. Hubbard, et al., Eds. (Springer Netherlands, 2016), pp. $7-45$.

90. J. D. Woodley, et al., Hurricane Allen's Impact on Jamaican Coral Reefs. Science 214, 749755 (1981).

91. R. D. Perkins, P. Enos, Hurricane Betsy in the Florida-Bahama Area: Geologic Effects and Comparison with Hurricane Donna. J. Geol. 76, 710-717 (1968).

92. K. J. Kroeker, et al., Ecological change in dynamic environments: Accounting for temporal environmental variability in studies of ocean change biology. Glob. Chang. Biol. 26, 54-67 (2020).

93. M. Ziegler, et al., Integrating environmental variability to broaden the research on coral responses to future ocean conditions. Glob. Chang. Biol. 27, 5532-5546 (2021).

94. A. Safaie, et al., High frequency temperature variability reduces the risk of coral bleaching. Nat. Commun. 9, 1671 (2018).

95. T. A. Oliver, S. R. Palumbi, Do fluctuating temperature environments elevate coral thermal tolerance? Coral Reefs 30, 429-440 (2011).

96. M. C. Bitter, et al., Fluctuating selection and global change: a synthesis and review on disentangling the roles of climate amplitude, predictability and novelty. Proc. Biol. Sci. 288, 20210727 (2021).

97. T. E. Reed, R. S. Waples, D. E. Schindler, J. J. Hard, M. T. Kinnison, Phenotypic plasticity and population viability: the importance of environmental predictability. Proc. Biol. Sci. 277, 3391-3400 (2010). 
98. B. E. Brown, Coral bleaching: causes and consequences. Coral Reefs 16, S129-S138 (1997).

99. B. T. Paradis, R. P. Henry, N. E. Chadwick, Compound effects of thermal stress and tissue abrasion on photosynthesis and respiration in the reef-building coral Acropora cervicornis (Lamarck, 1816). J. Exp. Mar. Bio. Ecol. 521, 151222 (2019).

100. E. H. Gladfelter, Skeletal development in Acropora cervicornis. Coral Reefs 3, 51-57 (1984).

101. I. M. Jimenez, M. Kühl, A. W. D. Larkum, P. J. Ralph, Heat budget and thermal microenvironment of shallow-water corals: Do massive corals get warmer than branching corals? Limnol. Oceanogr. 53, 1548-1561 (2008).

102. W. C. Million, S. O’Donnell, E. Bartels, C. D. Kenkel, Colony-Level 3D Photogrammetry Reveals That Total Linear Extension and Initial Growth Do Not Scale With Complex Morphological Growth in the Branching Coral, Acropora cervicornis. Frontiers in Marine Science 8, 384 (2021).

103. P. Cignoni, et al., MeshLab: an Open-Source Mesh Processing Tool (2008).

104. D. P. Manzello, R. Berkelmans, J. C. Hendee, Coral bleaching indices and thresholds for the Florida Reef Tract, Bahamas, and St. Croix, US Virgin Islands. Mar. Pollut. Bull. 54, $1923-$ 1931 (2007).

105. J. E. Walsh, I. Shapiro, T. L. Shy, On the variability and predictability of daily temperatures in the Arctic. Atmosphere-Ocean 43, 213-230 (2005).

106. J. Li, R. Ding, Temporal-spatial distribution of the predictability limit of monthly sea surface temperature in the global oceans. Int. J. Climatol. 33, 1936-1947 (2013).

107. R Core Team, R: A language and environment for statistical computing (2020).

108. T. M. Therneau, coxme: Mixed Effects Cox Models (Comprehensive R Archive Network (CRAN), 2020).

109. T. M. Therneau, T. Lumley, E. Atkinso, C. Crowson, survival: Survival Analysis (Comprehensive R Archive Network (CRAN), 2022).

110. R. H. B. Christensen, Regression Models for Ordinal Data (2019).

111. D. Bates, et al., Linear Mixed-Effects Models using “Eigen” and S4 (2022).

112. F. Yates, W. G. Cochran, The analysis of groups of experiments. J. Agric. Sci. 28, 556-580 (1938).

113. L. A. Dorn, E. H. Pyle, J. Schmitt, Plasticity to light cues and resources in Arabidopsis thaliana: testing for adaptive value and costs. Evolution 54, 1982-1994 (2000).

114. Y.-S. Su, M. Yajima, "R2jags: Using R to Run 'JAGS'” (2021). 
bioRxiv preprint doi: https://doi.org/10.1101/2022.03.04.483038; this version posted March 6, 2022. The copyright holder for this preprint (which was not certified by peer review) is the author/funder, who has granted bioRxiv a license to display the preprint in perpetuity. It is made available under aCC-BY-NC-ND 4.0 International license.

834

835

836

837 


\section{A}

Map daia Q2021 Bosge, INEC

$\uparrow$

\section{Sugarloaf Key}

Boca

Chica Key

Marker 32 Eastern Dry
Rocks

Big Pine Key

\section{$8 \quad 16 \mathrm{~km}$}

D 32.5

1

- E. Sambo - Looe Key

- Marker 32 - EDR

- W. Sambo - Maryland

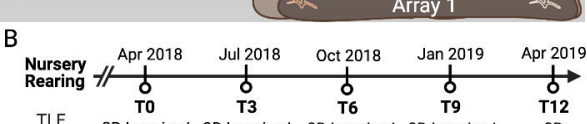

TLE

3D Imaging/3D Imaging/

3D Imaging/ 3D Imaging/

30

$\sim 8 \mathrm{~cm}$

TLE

TLE

TLE

TLE

Imaging

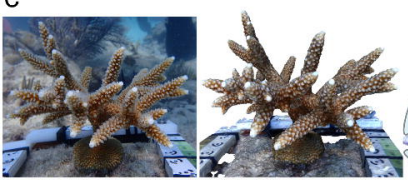

Image Capture
3D Modelling

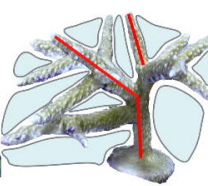

Phenotyping
- Big Pine - Bahia Honda

- Dave's Ledge

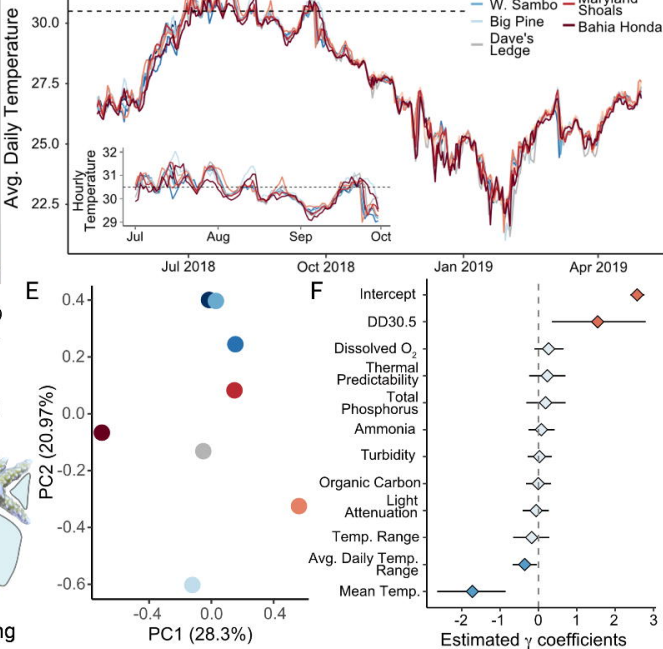

Estimated $\gamma$ coefficients 

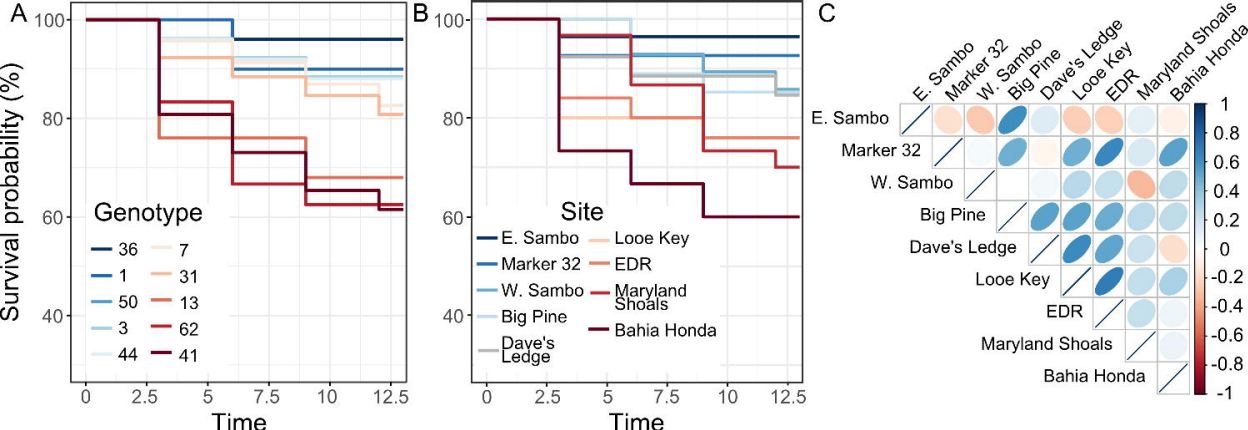

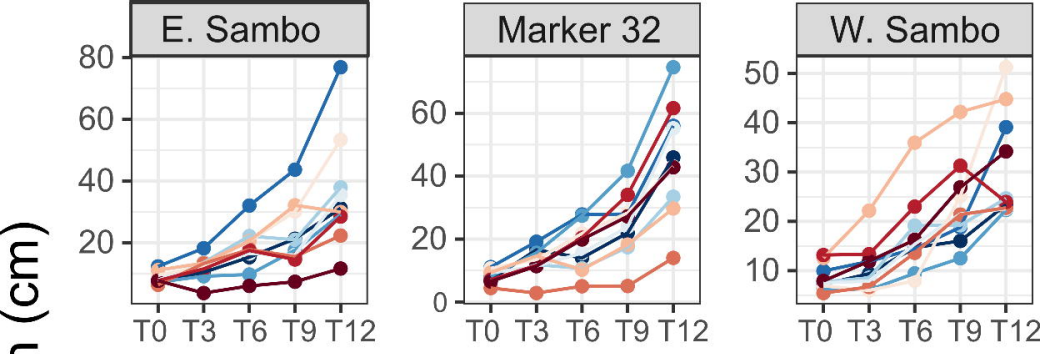

Genotype
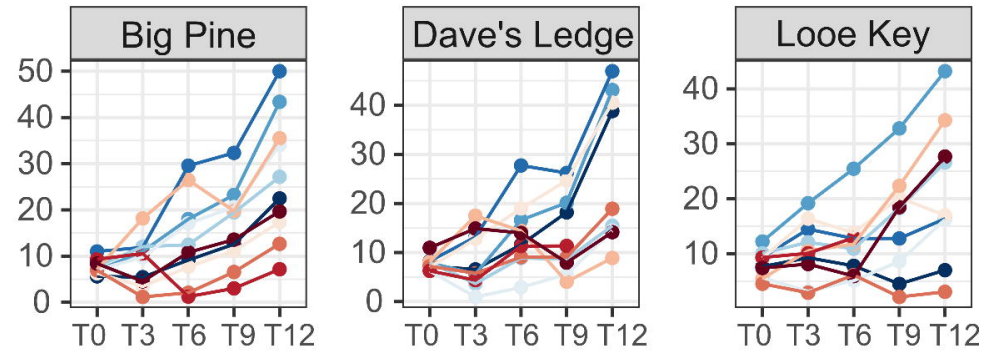

$-1$

$-50$

$-3$

44

7

$-31$

$-13$
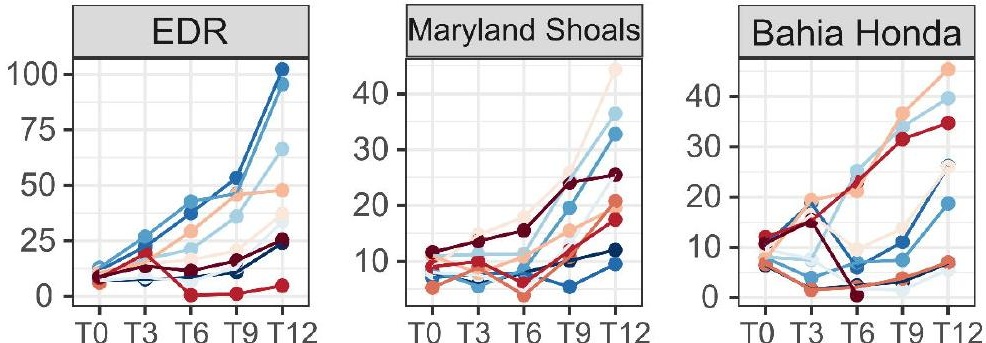

$\rightarrow 62$

$\rightarrow 41$ 
A $\quad$ RiskScore $\begin{array}{lllll}1.0 & 1.5 & 2.0 & 2.5\end{array}$
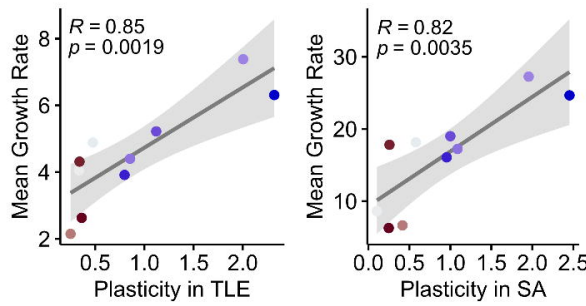

B Genotype

\begin{tabular}{|l|l|l}
\hline$\bullet$ & & 0 \\
\hdashline & $\bullet$ & 50 \\
\hline$\bullet$ & &
\end{tabular}

\begin{tabular}{l|lll|l}
44 & 0 & 31 & $\bullet$ & 62 \\
7 & $\bullet$ & 13 & $\bullet$ & 41
\end{tabular}

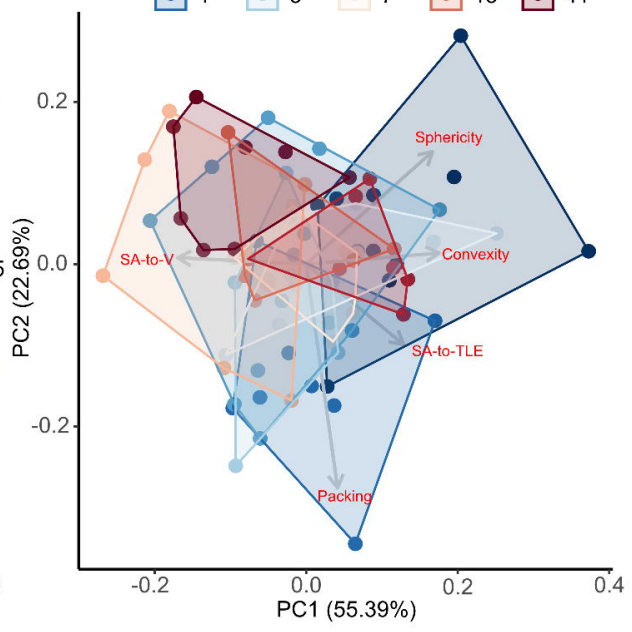

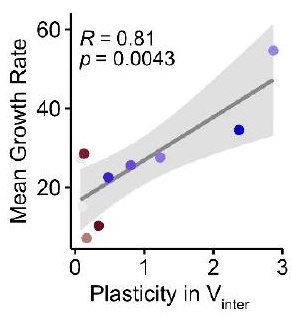

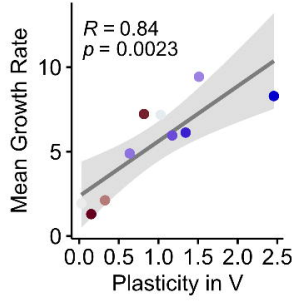

Plasticity in V 